\title{
Diagnostic Yield and Clinical Impact of Video Capsule Endoscopy in Patients with Chronic Diarrhea: A Korean Multicenter CAPENTRY Study
}

Hyun Joo Song ${ }^{1}$, Jeong Seop Moon², Seong Ran Jeon ${ }^{3}$, Jin-Oh Kim³ ${ }^{3}$ Jinsu Kim ${ }^{4}$, Dae Young Cheung ${ }^{4}$, Myung-Gyu Choi ${ }^{4}$, Yun Jeong Lim ${ }^{5}$, Ki-Nam Shim ${ }^{6}$, Byong Duk Ye ${ }^{7}$, Jae Hee Cheon ${ }^{8}$, Cheol Hee Park ${ }^{9}$, Hyun-Soo Kim ${ }^{10}$, Ji Hyun Kim ${ }^{11}$, Dong Kyung Chang ${ }^{12}$, Jae Hyuk Do ${ }^{13}$, Kyeong Ok Kim ${ }^{14}$, Byung Ik Jang ${ }^{14}$, and Sung-Jae Shin ${ }^{15}$; The Korean Gut Image Study Group

${ }^{\prime}$ Department of Internal Medicine, Jeju National University School of Medicine, Jeju, ${ }^{2}$ Department of Internal Medicine, Inje University College of Medicine, ${ }^{3}$ Department of Internal Medicine, Soonchunhyang University College of Medicine, ${ }^{4}$ Department of Internal Medicine, The Catholic University of Korea College of Medicine, Seoul, ${ }^{5}$ Department of Internal Medicine, Dongguk University College of Medicine, Goyang, ${ }^{6}$ Department of Internal Medicine, Ewha Womans University School of Medicine, ${ }^{7}$ Department of Gastroenterology, University of Ulsan College of Medicine, ${ }^{8}$ Department of Internal Medicine, Yonsei University College of Medicine, Seoul, ${ }^{9}$ Department of Internal Medicine, Hallym University College of Medicine, Anyang, ${ }^{10}$ Department of Internal Medicine, Yonsei University Wonju College of Medicine, Wonju, ${ }^{11}$ Department of Internal Medicine, Inje University College of Medicine, Busan, ${ }^{12}$ Department of Internal Medicine, Sungkyunkwan University School of Medicine, ${ }^{13}$ Department of Internal Medicine, Chung-Ang University College of Medicine, Seoul, ${ }^{14}$ Department of Internal Medicine, Yeungnam University College of Medicine, Daegu, and ${ }^{15}$ Department of Internal Medicine, Ajou University School of Medicine, Suwon, Korea

Background/Aims: In some cases, chronic diarrhea is unexplained, and small bowel disorders may be one of the causes. The aim of this study was to assess the diagnostic yield and clinical impact of video capsule endoscopy (VCE) in patients with chronic diarrhea. Methods: We retrospectively analyzed records from October 2002 to August 2013 in the VCE nationwide database registry $(n=2,964)$. Ninety-one patients from 15 medical centers ( 60 males and 31 females; mean age, $47 \pm 19$ years) were evaluated for VCE as a result of chronic diarrhea. Results: The duration of chronic diarrhea was $8.3 \pm 14.7$ months. The positive diagnostic yield of VCE was 42.9\% (39/91). However, 15.4\% (14/91) exhibited an inconsistent result, and $41.8 \%$ (38/91) were negative. Abnormal findings consistent with chronic diarrhea included erosions/aphthous ulcers (19.8\%), ulcers (17.6\%), mucosal erythema (3.3\%), edema (1.1\%), and luminal narrowing (1.1\%). The most common diagnoses were functional diarrhea associated with irritable bowel syndrome in 37 patients (40.7\%) and Crohn's disease in 18 patients (19.8\%). After VCE examination, the diagnosis was changed in $34.1 \%$ of the patients (31/91). Hematochezia (odds ratio [OR], 8.802; 95\% confidence interval [Cl], 2.126 to 36.441 ) and hypoalbuminemia (OR, 4.811; 95\% Cl, 1.241 to 18.655$)$ are predictive factors of a positive diagnostic yield. Conclusions: VCE had a favorable diagnostic yield and clinical impact on the management of patients with chronic diarrhea. (Gut Liver 2017;11:253-260)

Key Words: Capsule endoscopy; Diarrhea; Chronic

\section{INTRODUCTION}

Chronic diarrhea is defined as an increase in stool frequency and decrease in stool consistency for more than 4 weeks. It can be divided into three basic categories: watery, fatty, and inflammatory. Watery diarrhea is subdivided into osmotic, secretory, and functional. Fatty diarrhea is excess gas, steatorrhea and/or weight loss. Inflammatory diarrhea is Crohn's disease or ulcerative colitis. ${ }^{1}$ Small intestinal diseases are a common, though often overlooked cause of chronic diarrhea. Approximately 1\% of the Caucasian population is affected by celiac disease and a substantial portion of children living in poverty in the developing world are affected by environmental enteropathy. ${ }^{2}$

The main indications for small bowel video capsule endoscopy (VCE) are obscure gastrointestinal (GI) bleeding, suspected Crohn's disease, small bowel tumors, enteropathy induced by nonsteroidal anti-inflammatory drugs (NSAIDs), portal hypertensive enteropathy, celiac disease, unexplained iron deficiency anemia (IDA), and so forth. ${ }^{3}$ Most studies by VCE have been focused on obscure GI bleeding and abdominal pain. ${ }^{4-7}$ In the

Correspondence to: Jeong Seop Moon

Department of Internal Medicine, Inje University Seoul Paik Hospital, Inje University College of Medicine, 9 Mareunnae-ro, Jung-gu, Seoul 04551, Korea

Tel: +82-2-2270-0012, Fax: +82-2-2270-0312, E-mail: moonjs2@unitel.co.kr

Received on May 6, 2016. Revised on July 24, 2016. Accepted on July 24, 2016. Published online November 14,2016

pISSN 1976-2283 eISSN 2005-1212 https://doi.org/10.5009/gnl16231

@) This is an Open Access article distributed under the terms of the Creative Commons Attribution Non-Commercial License (http://creativecommons.org/licenses/by-nc/4.0) which permits unrestricted non-commercial use, distribution, and reproduction in any medium, provided the original work is properly cited. 
past, one small study $(n=20)$ revealed low diagnostic yield for the evaluation of patients with chronic abdominal pain and did not show any significant clinical value for diagnosing chronic abdominal pain. ${ }^{4}$ However, a recent large study $(n=243)$ showed increased diagnostic yield (23.0\%) of patients with chronic abdominal pain. ${ }^{6}$

However, it is increasingly used in other indications. Chronic diarrhea is sometimes unexplained, and small bowel disorder can be one of the causes. Small bowel disease such as Crohn's disease is an important cause for the evaluation of chronic diarrhea. To date, there have been few studies ${ }^{8,9}$ for the diagnostic role of VCE in patients with chronic diarrhea. Therefore, the aim of this study was to evaluate diagnostic yield and clinical impact of VCE patients in Korea.

\section{MATERIALS AND METHODS}

\section{Patients}

We retrospectively analyzed records from October 2002 to August 2013 in the VCE nationwide database registry. In Capsule Endoscopy Nationwide Database Registry (CAPENTRY) $(n=2,964)$, the reasons for VCE included obscure GI bleeding, Crohn's disease, small bowel tumor, unexplained abdominal pain, chronic diarrhea, ulcerative colitis, ischemic enteritis, Behçet's disease, cancer, unknown origin of weight loss, and protein losing enteropathy. Among them, patients with chronic diarrhea were 123 patients. After excluding insufficient data $(n=32)$, a total of 91 patients with chronic diarrhea of more than 1 month were included (Fig. 1). All data were collected from 15 medical centers. The data collected included clinical features of age, gender, body mass index (BMI), duration of diarrhea, weight loss, abdominal pain, hematochezia, underlying disease such as diabetes mellitus or thyroid disorder, drug history (NSAIDs, aspirin, anticoagulant, and steroid), previous VCE examination (upper endoscopy and colonoscopy), laboratory findings (hemoglobin level, erythrocyte sedimentation rate [ESR],
C-reactive protein [CRP], and albumin), radiologic findings, pathologic findings, and treatment outcomes. Use of prokinetics, antibiotics within 2 months, or laxatives was excluded. Primary outcome was diagnostic yield of clinically significant positive findings. Secondary outcome was clinical impact of decisionmaking treatment plan.

\section{VCE factors}

A total of 72 patients (79.1\%) underwent VCE by PillCam ${ }^{\mathrm{TM}}$ (SB1 and SB2; Given Imaging, Yokneam, Israel) whereas 19 patients (20.2\%) underwent VCE by Mirocam ${ }^{\mathrm{TM}}$ (IntroMedic Co., Ltd., Seoul, Korea). Battery duration mean time was 556.1 \pm 160.1 minutes, gastric emptying mean time was $39.8 \pm 47.4$ minutes, and small bowel transit mean time was $323.9 \pm 136.4$ minutes. Cecal complete rate was $82.4 \%$ (75/91) and capsule retention rate was $1.1 \%(1 / 91)$ in a patient with Crohn's disease. Bowel preparation methods were PEG 2 L in 48 (52.7\%), nothing per oral in 18 (19.8\%), PEG 4 L in 17 (18.7\%), and so forth. Bowel preparation was excellent in 25 (27.5\%), and good in 46 (50.5\%). Even though bowel preparation was fair in 12 (13.2\%), and poor in eight patients (8.8\%), it did not mean inconsistent results.

\section{Statistics}

Data were represented as mean \pm standard deviation for continuous variables and number (\%) for categorical data. Statistical analysis was performed using Student t-test, chi-square test, and Fisher exact test. Multiple logistic regression analysis was used to identify risk factors for positive diagnostic yields and effect estimates are presented as odds ratio (OR) and 95\% confidence interval (CI). The data were analyzed using SPSS for Windows version 18.0 (SPSS Inc., Chicago, IL, USA), and p-value $<0.05$ was considered significant.

\section{Ethics statement}

The Institutional Review Board of Jeju National University Hospital approved the study protocol (IRB number: 2013-10-

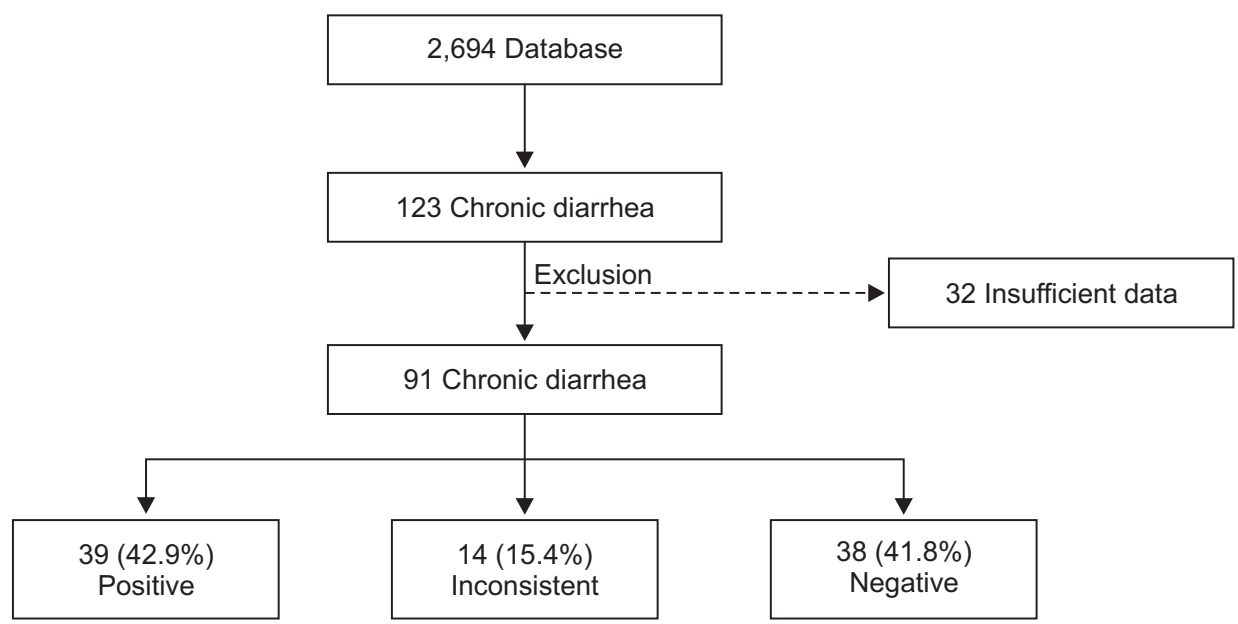

Fig. 1. Flow chart of chronic diarrhea according to the results. 
008). Written informed consent was not required because this was a retrospective chart-review study.

\section{RESULTS}

\section{Demographic characteristics of patients}

A total of 91 patients (60 males and 31 females; mean age, $47 \pm 19$ year) were evaluated. The average duration of diarrhea was $8.3 \pm 14.7$ months (range, 1 to 120 months). Significant baseline characteristics include: 56\% with weight loss, 69.2\% with abdominal pain and 15.4\% with hematochezia (Table 1). Drug history was not remarkable. Prior to VCE, patients underwent colonoscopy (81.3\%) and abdominopelvic computed tomography (57.1\%). Anemia is defined as hemoglobin levels $<12.0 \mathrm{~g} / \mathrm{dL}$ in women and $<13.0 \mathrm{~g} / \mathrm{dL}$ in men according to the World Health Organization (WHO). ${ }^{10}$ Anemia was found in 40.7\% (37/91). ESR and CRP levels were increased in 24.2\% and 28.6\%, respectively. Positive inflammatory markers were defined as an increase in leukocytes $\left(>10,000 / \mathrm{mm}^{3}\right)$ or CRP $(\geq 0.4$ $\mathrm{mg} / \mathrm{dL}$ ). Hypoalbuminemia (albumin $<3.0 \mathrm{~g} / \mathrm{dL}$ ) was found in $16.5 \%$ of patients (15/91).

\section{Diagnostic yield and positive findings of VCE}

The positive diagnostic yield of VCE was 42.9\% (39/91). However, 15.4\% (14/91) showed inconsistent result, and 41.8\% (38/91) were negative (Fig. 1). Abnormal findings consistent with chronic diarrhea include erosions/aphthous ulcers (19.8\%), ulcers (17.6\%), mucosal erythema (3.3\%), edema (1.1\%), and luminal narrowing (1.1\%). Although nonneoplastic polyp (6.6\%), angiodysplasia (5.5\%), submucosal tumor (4.4\%), and diverticulum (1.1\%) were found, they were inconsistent with chronic diarrhea (Fig. 2).

Prior to VCE examination, 42 patients (46.2\%) showed normal findings. The second most common pre-VCE diagnosis had 17 suspected and 11 established Crohn's disease in 28 patients
Table 1. Baseline Patient Characteristics of 91 Patients

\begin{tabular}{|c|c|}
\hline Variable & Value \\
\hline Age, yr & $47 \pm 19(14-83)$ \\
\hline Male:female & $60(65.9): 31(34.1)$ \\
\hline BMI, $\mathrm{kg} / \mathrm{m}^{2}$ & $20.9 \pm 3.1$ \\
\hline Duration of chronic diarrhea, mo & $8.3 \pm 14.7(1-120)$ \\
\hline Weight loss & $51(56)$ \\
\hline Abdominal pain & $63(69.2)$ \\
\hline Hematochezia & $14(15.4)$ \\
\hline Diabetes mellitus & $5(5.5)$ \\
\hline Thyroid disorder & 0 \\
\hline \multicolumn{2}{|l|}{ Drug history } \\
\hline NSAIDs & $2(2.2)$ \\
\hline Aspirin & $3(3.3)$ \\
\hline Anticoagulant & $1(1.1)$ \\
\hline Steroid & $2(2.2)$ \\
\hline \multicolumn{2}{|l|}{ Prior VCE exam } \\
\hline Upper endoscopy & $68(74.7)$ \\
\hline Colonoscopy & $74(81.3)$ \\
\hline Abdominopelvic CT & $52(57.1)$ \\
\hline Small bowel series & $18(19.8)$ \\
\hline Double balloon enteroscopy & $2(2.2)$ \\
\hline Anemia* & $37(40.7)$ \\
\hline $\mathrm{WBC}>10,000 / \mathrm{mm}^{3}$ & $4(4.4)$ \\
\hline $\mathrm{ESR}>20 \mathrm{~mm} / \mathrm{hr}$ & $22(24.2)$ \\
\hline $\mathrm{CRP} \geq 0.4 \mathrm{mg} / \mathrm{dL}$ & $26(28.6)$ \\
\hline Positive inflammatory markers & $28(30.8)$ \\
\hline Albumin <3.0 g/dL & $15(16.5)$ \\
\hline
\end{tabular}

Data are presented as mean \pm SD (range) or number (\%).

BMI, body mass index; NSAIDs, nonsteroidal anti-inflammatory drugs; VCE, video capsule endoscopy; CT, computed tomography; WBC, white blood cell; ESR, erythrocyte sedimentation rate; CRP, C-reactive protein.

*Male, hemoglobin $<13.0 \mathrm{~g} / \mathrm{dL}$; female, hemoglobin $<12.0 \mathrm{~g} / \mathrm{dL}$.

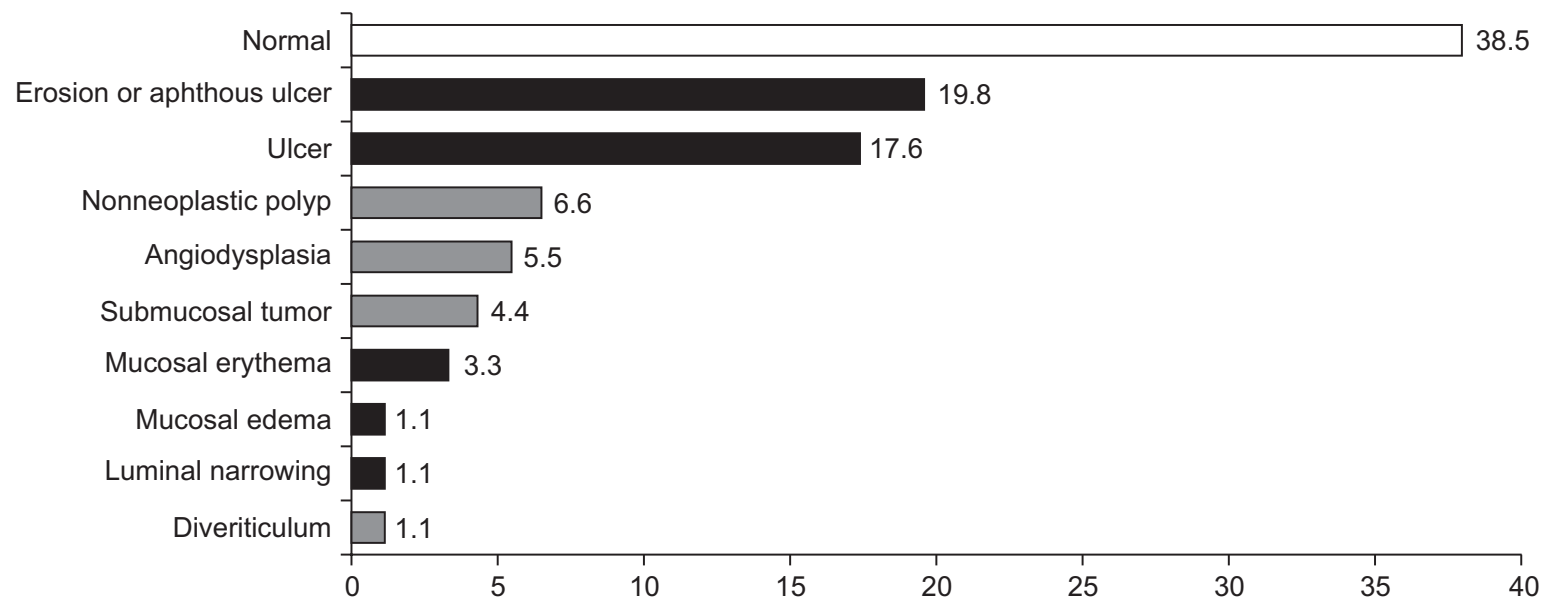

Fig. 2. Positive, inconsistent and negative video capsule endoscopy findings of chronic diarrhea (black bar, positive; gray bar, inconsistent; white bar, negative). 
(30.8\%), intestinal tuberculosis in eight (8.8\%), enteritis in two (2.2\%), and so forth. However, most common post-VCE diagnoses were functional diarrhea associated with irritable bowel syndrome in 37 (40.7\%) and Crohn's disease in 18 patients (19.8\%). Eosinophilic enteritis in five (5.5\%), small bowel tumor in four (4.4\%), intestinal tuberculosis in two (2.2\%), NSAIDs-induced enteropathy in two (2.2\%), Behçet's disease in one (1.1\%), celiac disease in one (1.1\%), and HIV enteropathy in one patient

Table 2. Final Diagnosis and Video Capsule Endoscopy Findings in Patients with Chronic Diarrhea

\begin{tabular}{|c|c|c|}
\hline Final diagnosis & No. $(\%)$ & VCE findings \\
\hline Irritable bowel syndrome & $37(40.7)$ & Normal \\
\hline \multirow[t]{8}{*}{ Crohn's disease } & $18(19.8)$ & Erosion/aphthous ulcer (9) \\
\hline & & Ulcer (7) \\
\hline & & Mucosal nodularity (4) \\
\hline & & Luminal narrowing (2) \\
\hline & & Blood in the lumen (1) \\
\hline & & Mucosal hemorrhage (1) \\
\hline & & Ulcerative mass (1) \\
\hline & & Mucosal edema (1) \\
\hline \multirow[t]{4}{*}{ Eosinophilic enteritis } & $5(5.5)$ & Erosion/aphthous ulcer (2) \\
\hline & & Mucosal erythema (2) \\
\hline & & Ulcer (1) \\
\hline & & Mucosal congestion (1) \\
\hline Small bowel tumor & $4(4.4)$ & Submucosal mass (4) \\
\hline \multirow[t]{3}{*}{ Erosive enteropathy } & $2(2.2)$ & Ulcer (1) \\
\hline & & Erosion/aphthous ulcer (1) \\
\hline & & Mucosal edema (1) \\
\hline \multirow[t]{2}{*}{ Intestinal tuberculosis } & $2(2.2)$ & Erosion/aphthous ulcer (1) \\
\hline & & Normal (1) \\
\hline $\begin{array}{l}\text { NSAIDs-induced } \\
\text { enteropathy }\end{array}$ & $2(2.2)$ & Erosion/aphthous ulcer (1) \\
\hline \multirow[t]{2}{*}{ Behçet's disease } & $1(1.1)$ & Ulcer (1) \\
\hline & & Erosion/aphthous ulcer (1) \\
\hline \multirow[t]{2}{*}{ Celiac disease } & $1(1.1)$ & Erosion/aphthous ulcer (1) \\
\hline & & Mucosal edema (1) \\
\hline HIV-induced enteropathy & $1(1.1)$ & Mucosal erythema (1) \\
\hline Protein-losing enteropathy & $1(1.1)$ & Mucosal edema, severe (1) \\
\hline Collagenous colitis & $1(1.1)$ & Mucosal erythema (1) \\
\hline Henoch-Schönlein purpura & $1(1.1)$ & Ulcer (1) \\
\hline Autoimmune enteritis & $1(1.1)$ & Ulcer (1) \\
\hline \multirow[t]{3}{*}{ Nonspecific enteritis } & $2(2.2)$ & Ulcer (1) \\
\hline & & Erosion/aphthous ulcer (1) \\
\hline & & Mucosal edema (1) \\
\hline
\end{tabular}

With the exception of irritable bowel syndrome, this table indicated positive video capsule endoscopy findings.

VCE, video capsule endoscopy; NSAIDs, nonsteroidal anti-inflammatory drugs; HIV, human immunodeficiency virus.
(1.1\%) were also found. Final diagnoses and VCE findings were demonstrated in Table 2. Among patients with positive findings, Crohn's disease was the most common. Pathologic confirmation was done in 10 patients (11.1\%).

After VCE examination, the diagnosis was changed in $34.1 \%$ of patients (31/91) and 70.3\% of patients (64/91) underwent medical treatment. The change of final diagnosis according to VCE findings was shown in Fig. 3. A total of 31 cases with pre-VCE diagnoses included irritable bowel syndrome $(n=11)$, suspected Crohn's disease $(n=11)$, suspected intestinal tuberculosis $(n=6)$, necrotizing enteritis $(n=1)$, celiac disease $(n=1)$, and chronic diarrhea with rectal bleeding $(n=1)$.

\section{Factors analysis associated with positive diagnostic yields of VCE}

Comparison of clinical characteristics between positive and inconsistent or negative VCE results groups is shown in Table 3. There were no significant differences in age, gender, BMI, weight loss, presence of abdominal pain, anemia, and positive inflammatory markers. In addition, bowel preparation quality and the sort of device were not significantly different between the two groups. However, duration of chronic diarrhea had a tendency toward increased duration in positive results group than in inconsistent or negative results group $(10.4 \pm 20.3$ vs $6.6 \pm 8.0, p=0.088)$. Hematochezia $(28.2 \%$ vs $5.8 \%, p=0.006)$ and hypoalbuminemia (albumin $<3.0 \mathrm{~g} / \mathrm{dL} ; 25.6 \%$ vs $9.6 \%$, $\mathrm{p}=0.050$ ) were more remarkable for positive results group than inconsistent or negative results group, respectively. According to multiple logistic regression analysis for risk factors of positive diagnostic yield after adjusting for age, gender, weight loss, abdominal pain, anemia and positive inflammatory markers, hematochezia (OR, 8.802; 95\% CI, 2.126 to 36.441), and hypoalbuminemia (OR, 4.811; 95\% CI, 1.241 to 18.655$)$ are independent risk factors for predicting positive diagnostic yield (Table 4).

\section{Clinical characteristics and VCE findings of Crohn's disease}

Clinical characteristics and VCE findings of 18 patients with Crohn's disease after VCE examination were summarized in Table 5. Among them, pre-VCE diagnosis was found in 11 with established Crohn's disease, six suspected Crohn's disease, and one necrotizing enteritis. Most patients had symptoms of abdominal pain and weight loss. One-third $(n=6)$ of suspected Crohn's disease was confirmed as Crohn's disease after VCE examination. Therefore, VCE is very useful for confirmation of suspected Crohn's disease after examination of small bowel. Fig. 4 demonstrated a suspected Crohn's disease case (Table 5. No. 17) with VCE confirmation of Crohn's disease.

\section{DISCUSSION}

Most studies by VCE have been focused on obscure GI bleed- 


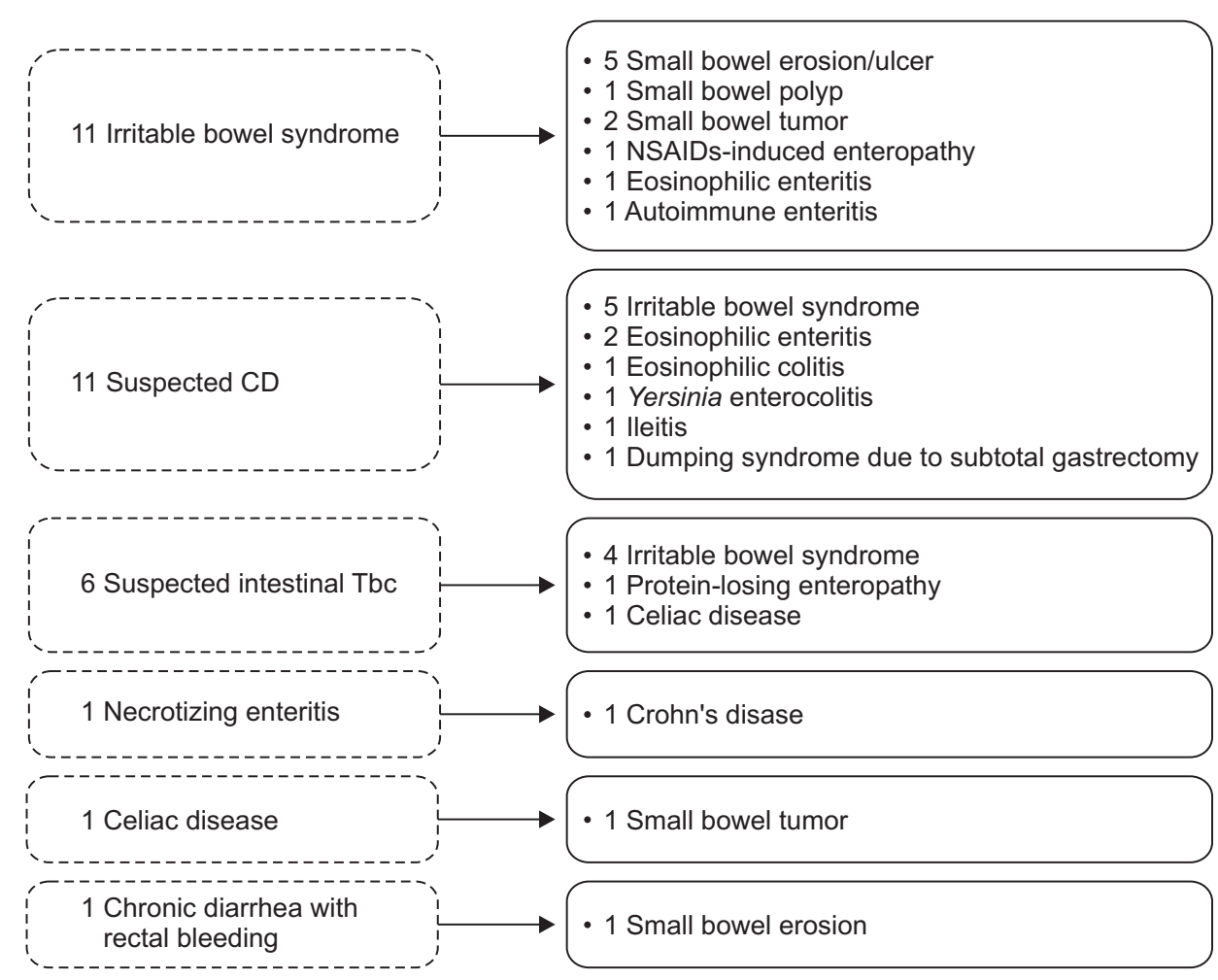

Fig. 3. Changes in diagnosis before and after video capsule endoscopy. NSAIDs, nonsteroidal anti-inflammatory drugs; $\mathrm{CD}$, Crohn's disease; Tbc, tuberculosis.

Table 3. Comparison of Clinical Characteristics between the Positive Result and Inconsistent or Negative Video Capsule Endoscopy Result Groups

\begin{tabular}{|c|c|c|c|}
\hline & Positive results $(\mathrm{n}=39)$ & Inconsistent or negative results $(n=52)$ & p-value \\
\hline Age, yr & $46 \pm 19$ & $49 \pm 19$ & 0.823 \\
\hline Gender & & & 0.825 \\
\hline Male & $25(64.1)$ & $35(67.3)$ & \\
\hline Female & $14(35.9)$ & $17(32.7)$ & \\
\hline BMI, $\mathrm{kg} / \mathrm{m}^{2}$ & $21.3 \pm 2.9$ & $20.6 \pm 3.3$ & 0.660 \\
\hline Duration of chronic diarrhea, mo & $10.4 \pm 20.3$ & $6.6 \pm 8.0$ & 0.088 \\
\hline Weight loss & $22(57.9)$ & $29(56.9)$ & 1.000 \\
\hline Abdominal pain & $28(71.8)$ & $35(67.3)$ & 0.819 \\
\hline Hematochezia & $11(28.2)$ & $3(5.8)$ & 0.006 \\
\hline Anemia* & $18(46.2)$ & $19(46.5)$ & 0.394 \\
\hline Positive inflammatory markers & $15(38.5)$ & $13(25.0)$ & 0.251 \\
\hline Albumin $<3.0 \mathrm{~g} / \mathrm{dL}$ & $10(25.6)$ & $5(9.6)$ & 0.050 \\
\hline Adequate bowel preparation (excellent/good) & $33(84.6)$ & $38(73.1)$ & 0.188 \\
\hline Device of VCE & & & 0.333 \\
\hline PillCam by given imaging & $29(74.4)$ & $43(82.7)$ & \\
\hline Miro by introdedic & $10(25.6)$ & $9(17.3)$ & \\
\hline
\end{tabular}

Data are presented as mean \pm SD or number $(\%)$.

BMI, body mass index; VCE, video capsule endoscopy.

*Male, hemoglobin $<13.0 \mathrm{~g} / \mathrm{dL}$; female, hemoglobin $<12.0 \mathrm{~g} / \mathrm{dL}$.

ing. The role of VCE in the assessment of other nonbleeding indications and particularly in patients with chronic diarrhea is uncertain. ${ }^{11}$ Therefore, the aim of this study is to explain the diagnostic yield and clinical impact of VCE in patients with chronic diarrhea. According to a previous study, the diagnos- tic yield of VCE in patients with chronic diarrhea was lower compared to obscure GI bleeding (25\% vs 52\%, respectively, $\mathrm{p}=0.013$; CI, 1.33 to 7.83$).^{12}$ In our study, the positive diagnostic yield of VCE was 42.9\% (39/91). This study showed higher diagnostic yield compared with previous report (42.9\% vs 25.0\%). 
Table 4. Multiple Logistic Regression Analysis for Risk Factors of Positive Diagnostic Yields

\begin{tabular}{|c|c|c|c|}
\hline & OR & $95 \% \mathrm{CI}$ & $\mathrm{p}$-value \\
\hline Weight loss & 0.708 & $0.265-1.889$ & 0.491 \\
\hline Abdominal pain & 1.012 & $0.311-3.293$ & 0.985 \\
\hline Hematochezia & 8.802 & $2.126-36.441$ & 0.003 \\
\hline Anemia & 1.271 & $0.450-3.587$ & 0.650 \\
\hline Positive inflammatory markers & 1.502 & $0.524-4.310$ & 0.449 \\
\hline Albumin $<3.0 \mathrm{~g} / \mathrm{dL}$ & 4.811 & $1.241-18.655$ & 0.023 \\
\hline
\end{tabular}

Logistic analysis: adjusted for age, gender, weight loss, abdominal pain, anemia and positive inflammatory markers.

OR, odds ratio; $\mathrm{CI}$, confidence interval.

Table 5. Clinical Characteristics and Video Capsule Endoscopy Findings of 18 Patients with Crohn's Disease

\begin{tabular}{|c|c|c|c|c|c|c|c|c|c|c|c|c|c|}
\hline \multirow{2}{*}{$\begin{array}{c}\text { Case } \\
\text { no. }\end{array}$} & \multirow{2}{*}{$\begin{array}{l}\text { Age, } \\
\text { yr }\end{array}$} & \multirow[b]{2}{*}{ Sex } & \multirow{2}{*}{$\begin{array}{l}\text { Duration } \\
\text { of Sx, mo }\end{array}$} & \multirow{2}{*}{$\begin{array}{l}\mathrm{BMI}, \\
\mathrm{kg} / \mathrm{m}^{2}\end{array}$} & \multirow{2}{*}{$\begin{array}{l}\text { Abdominal } \\
\text { pain }\end{array}$} & \multirow{2}{*}{$\begin{array}{l}\text { Weight } \\
\text { loss, } \\
\text { kg }\end{array}$} & \multicolumn{5}{|c|}{ Laboratory findings } & \multirow[b]{2}{*}{ Pre-VCE Dx } & \multirow{2}{*}{$\begin{array}{l}\text { Positive } \\
\text { VCE } \\
\text { findings }\end{array}$} \\
\hline & & & & & & & $\begin{array}{l}\mathrm{Hb}, \\
\mathrm{g} / \mathrm{dL}\end{array}$ & $\begin{array}{l}\mathrm{WBC} \\
/ \mathrm{mm}^{3}\end{array}$ & $\begin{array}{l}\mathrm{ESR}, \\
\mathrm{mm} / \mathrm{hr}\end{array}$ & $\begin{array}{l}\text { CRP, } \\
\mathrm{mg} / \mathrm{dL}\end{array}$ & $\begin{array}{l}\text { Albumin, } \\
\text { g/dL }\end{array}$ & & \\
\hline 1 & 44 & M & 2 & 23.7 & Yes & Yes (10) & 12.7 & 9,600 & 96 & 3.37 & 4.2 & Established CD & Yes \\
\hline 2 & 16 & M & 3 & 16.4 & Yes & Yes (6) & 10.0 & 7,200 & 102 & 9.62 & 2.9 & Established CD & Yes \\
\hline 3 & 26 & M & 3 & 17.4 & Yes & Yes (7) & 10.6 & 7,900 & 74 & 1.16 & 2.4 & Established CD & Yes \\
\hline 4 & 47 & $\mathrm{~F}$ & 8 & 18.7 & Yes & Yes (8) & 10.5 & 4,800 & 23 & 0.62 & 3.0 & Suspected CD & Yes \\
\hline 5 & 21 & M & 2 & 18.5 & Yes & Yes (8) & 15.3 & 7,600 & 4 & 0.01 & 4.8 & Established CD & No \\
\hline 6 & 17 & M & 1 & 22.9 & Yes & Yes (3) & 14.9 & 4,100 & 3 & 0.19 & 4.4 & Established CD & No \\
\hline 7 & 36 & M & 1 & 19.3 & Yes & Yes (5) & 12.7 & 7,400 & 13 & 3.00 & 3.5 & Established CD & Yes \\
\hline 8 & 80 & M & 4 & 20.8 & Yes & Yes (5) & 10.1 & 7,800 & 40 & 7.10 & 2.3 & Necrotizing enteritis & Yes \\
\hline 9 & 57 & M & 12 & 23.0 & Yes & Yes (5) & 14.7 & 4,300 & 23 & 0.10 & 3.5 & Suspected CD & Yes \\
\hline 10 & 71 & $\mathrm{~F}$ & 2 & 23.7 & Yes & No & 10.4 & 7,800 & 26 & 0.09 & 3.4 & Suspected CD & Yes \\
\hline 11 & 17 & M & 6 & 19.0 & Yes & Yes (12) & 11.9 & 9,200 & NA & 3.90 & 4.2 & Established CD & Yes \\
\hline 12 & 23 & M & 13 & 24.8 & Yes & Yes (14) & 11.0 & 6,300 & 2 & 0.10 & 4.9 & Established CD & Yes \\
\hline 13 & 30 & M & 1 & 17.6 & Yes & Yes (7) & 14.8 & 7,800 & NA & 0.20 & 3.9 & Established CD & Yes \\
\hline 14 & 16 & M & 2 & 20.3 & Yes & No & 12.9 & 14,500 & NA & 1.90 & 3.5 & Established CD & Yes \\
\hline 15 & 30 & M & 8 & 20.0 & Yes & No & 15.1 & 5,600 & 6 & 0.10 & 4.0 & Suspected CD & Yes \\
\hline 16 & 27 & M & 5 & 23.9 & No & Yes (1) & 16.0 & 9,800 & 12 & 0.03 & 3.9 & Suspected CD & Yes \\
\hline 17 & 68 & M & 9 & 17.8 & No & Yes (4) & 9.0 & 7,640 & NA & 0.03 & 3.7 & Suspected CD & Yes \\
\hline 18 & 35 & M & 36 & 23.5 & Yes & No & 11.6 & 5,470 & 37 & 0.71 & 4.2 & Established CD & Yes \\
\hline
\end{tabular}

Sx, symptom; BMI, body mass index; Hb, hemoglobin; WBC, white blood cell; ESR, erythrocyte sedimentation rate; CRP, C-reactive protein; VCE, video capsule endoscopy; Dx, diagnosis; M, male; CD, Crohn's disease; F, female; NA, not applicable.

A study regarding diagnostic tools in the evaluation of nonbleeding indications $(n=165)$ showed the most common indications of VCE were chronic abdominal pain alone $(n=33)$ or combined with chronic diarrhea $(n=31)$ and chronic diarrhea alone $(\mathrm{n}=30) .{ }^{13}$ VCE findings were positive, suspicious and negative in 73 (44.2\%), 13 (7.9\%), and 79 (47.9\%) patients, respectively. The diagnostic yields was as follows: celiac disease (100\%, 10/10), suspected Crohn's disease (83.3\%, 5/6), chronic abdominal pain and chronic diarrhea (41.9\%, 13/31), established Crohn's disease (33.3\%, 2/6), chronic diarrhea alone (26.7\%, 8/30), chronic abdominal pain alone $(24.2 \%, 8 / 33)$ and other indications $(23.1 \%$, $3 / 13)(p<0.005)$. Therefore, VCE is a useful tool in the evaluation of patients with nonbleeding indications. In addition, the out- come of most patients with negative findings was excellent.

In the present study, 40.7\% (37/91) of patients with chronic diarrhea were ultimately diagnosed with irritable bowel syndrome. Even though VCE has no role in the diagnosis of irritable bowel syndrome, it has potential impact for the differential diagnosis of small bowel disease. Inconsistent results such as nonneoplastic polyp (6.6\%), angiodysplasia (5.5\%), and diverticulum $(1.1 \%)$ were not associated with chronic diarrhea and should be interpreted with caution. Secondly, the most common cause of chronic diarrhea in considering evaluation for small bowel was Crohn's disease (19.8\%). The most common positive findings were erosions or aphthous ulcers (19.8\%), ulcers (17.6\%), mucosal erythema (3.3\%), edema (1.1\%), and luminal narrow- 

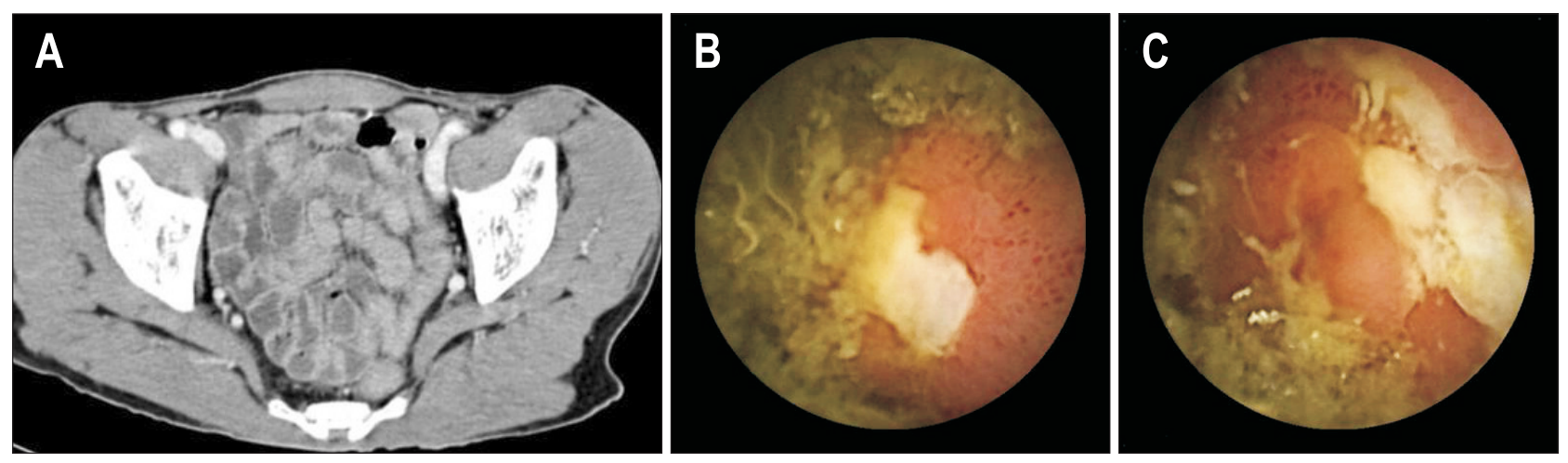

Fig. 4. Video capsule endoscopy (VCE) findings of a 68-year-old male who had chronic diarrhea for 9 months with a 4-kg weight loss. Pre-VCE examinations via upper endoscopy and colonoscopy were negative, including abdominopelvic computed tomography findings (A). However, VCE indicated multiple ulcers with a cobblestone appearance from the mid-jejunum to proximal ileum $(\mathrm{B}, \mathrm{C})$. This case demonstrated a VCE confirmation of chronic diarrhea as a result of Crohn's disease.

ing (1.1\%), which were mostly suggestive of Crohn's disease. On the contrary, some suspected Crohn's diseases were found to be normal after VCE examination. This result was similar to a previous report as $12.5 \%$ of patients who underwent VCE $(n=109)$ had Crohn's disease, among all who had diarrhea $(n=8) .{ }^{14}$ VCE could diagnose small bowel Crohn's disease in nearly one third of patients with symptoms of Crohn's inconclusive diagnosis by conventional methods. ${ }^{15}$ In this study, six suspected Crohn's disease were ultimately diagnosed with Crohn's disease, which was one third of 18 Crohn's disease cases. Therefore, VCE is the most accurate diagnostic tool for detecting mucosal lesions in suspected or established Crohn's disease, according the 2015 Korean guidelines (strong recommendations, low quality evidence). ${ }^{16}$ In our study, one patient with capsule retention had Crohn's disease.

Some diagnoses $(34.1 \%, 31 / 91)$ were changed according to Fig. 3. Most commonly suspected of chronic diarrhea before VCE examination were irritable bowel syndrome, Crohn's disease, and intestinal tuberculosis in this study. However, approximately one-third $(34.1 \%, 31 / 91)$ of diagnoses were changed following VCE examination. Therefore, VCE has a useful role in evaluating and confirming the etiology of patients with chronic diarrhea.

We analyzed factors associated with positive diagnostic yield of VCE. Interestingly, hematochezia (OR, 8.802; 95\% CI, 2.126 to 36.441 ), and hypoalbuminemia (OR, 4.811; 95\% CI, 1.241 to 18.655) are remarkable independent risk factors for predicting positive diagnostic yield according to multiple logistic regression analysis. However, weight loss, abdominal pain, anemia and positive inflammatory markers were not significant. These results were different from previous studies regarding chronic abdominal pain. ${ }^{9,17}$

Our study has some limitations. First, it was a retrospective study with various institutes; therefore, some laboratory data were not sufficient for analysis. Significant interobserver variability might exist among the gastroenterologists. The final diagnoses were also heterogeneous, it was difficult to analyze. Second, the patients included may have selection bias, because VCE was not covered by insurance during the study period (October 2002 to August 2013). Therefore, patients might have been enrolled for VCE evaluation of chronic diarrhea based on their ability to pay. Third, the period of study is too long for adequate results. Sample size may be too small to evaluate the diagnostic yield of VCE. However, this study has value as the first multicenter study regarding diagnostic yield and clinical impact of VCE in patients with chronic diarrhea based on CAPENTRY in Korea.

In conclusions, these results suggest that VCE can be helpful in patients suffering from chronic diarrhea that cannot be explained by established examinations. Overall, the positive diagnostic yield of VCE was 42.9\%. After VCE, the previous diagnosis was changed in 34.1\% patients (31/91). Among patients with positive findings, Crohn's disease was the most common. VCE had favorable diagnostic yield and clinical impact in patients with chronic diarrhea. Due to the small sample size and lengthy study period, further study is recommended with larger sample and shorter study period for confirmation of results.

\section{CONFLICTS OF INTEREST}

No potential conflict of interest relevant to this article was reported.

\section{ACKNOWLEDGEMENTS}

This work was supported by the research grant of Jeju National University in 2014.

\section{REFERENCES}

1. Juckett G, Trivedi R. Evaluation of chronic diarrhea. Am Fam Physician 2011;84:1119-1126. 
2. Murray JA, Rubio-Tapia A. Diarrhoea due to small bowel diseases. Best Pract Res Clin Gastroenterol 2012;26:581-600.

3. Pennazio M, Spada C, Eliakim R, et al. Small-bowel capsule endoscopy and device-assisted enteroscopy for diagnosis and treatment of small-bowel disorders: European Society of Gastrointestinal Endoscopy (ESGE) Clinical Guideline. Endoscopy 2015;47:352376.

4. Bardan E, Nadler M, Chowers Y, Fidder H, Bar-Meir S. Capsule endoscopy for the evaluation of patients with chronic abdominal pain. Endoscopy 2003;35:688-689.

5. Keuchel M, Hagenmüller F. Video capsule endoscopy in the work-up of abdominal pain. Gastrointest Endosc Clin N Am 2004;14:195-205.

6. Yang L, Chen Y, Zhang B, et al. Increased diagnostic yield of capsule endoscopy in patients with chronic abdominal pain. PLoS One 2014;9:e87396.

7. Egnatios J, Kaushal K, Kalmaz D, Zarrinpar A. Video capsule endoscopy in patients with chronic abdominal pain with or without associated symptoms: a retrospective study. PLoS One 2015;10: e0126509.

8. May A, Manner H, Schneider M, Ipsen A, Ell C. Prospective multicenter trial of capsule endoscopy in patients with chronic abdominal pain, diarrhea and other signs and symptoms (CEDAP-Plus Study). Endoscopy 2007;39:606-612.

9. Katsinelos P, Fasoulas K, Beltsis A, et al. Diagnostic yield and clinical impact of wireless capsule endoscopy in patients with chronic abdominal pain with or without diarrhea: a Greek multicenter study. Eur J Intern Med 2011;22:e63-e66.
10. Cappellini MD, Motta I. Anemia in clinical practice-definition and classification: does hemoglobin change with aging? Semin Hematol 2015;52:261-269.

11. Rondonotti E, Soncini M, Girelli C, et al. Small bowel capsule endoscopy in clinical practice: a multicenter 7-year survey. Eur J Gastroenterol Hepatol 2010;22:1380-1386.

12. Kalantzis N, Papanikolaou IS, Giannakoulopoulou E, et al. Capsule endoscopy; the cumulative experience from its use in 193 patients with suspected small bowel disease. Hepatogastroenterology 2005;52:414-419.

13. Katsinelos P, Tziomalos K, Fasoulas K, et al. Can capsule endoscopy be used as a diagnostic tool in the evaluation of nonbleeding indications in daily clinical practice? A prospective study. Med Princ Pract 2011;20:362-367.

14. Freitas GP, Teixeira N, Feldman G. Capsule endoscopy in clinical practice: four years of experience from a single center. Arq Gastroenterol 2011;48:220-222.

15. Petruzziello C, Calabrese E, Onali S, et al. Small bowel capsule endoscopy vs conventional techniques in patients with symptoms highly compatible with Crohn's disease. J Crohns Colitis 2011;5: 139-147.

16. Park SK, Ye BD, Kim KO, et al. Guidelines for video capsule endoscopy: emphasis on Crohn's disease. Clin Endosc 2015;48:128135.

17. Shim KN, Kim YS, Kim KJ, et al. Abdominal pain accompanied by weight loss may increase the diagnostic yield of capsule endoscopy: a Korean multicenter study. Scand J Gastroenterol 2006;41:983-988. 